\title{
Watching Aggressive, Attractive, Female Protagonists Shapes Gender Roles for Women Among Male and Female Undergraduate Viewers
}

\author{
Laramie D. Taylor • Tiffany Setters
}

Published online: 30 March 2011

(C) The Author(s) 2011. This article is published with open access at Springerlink.com

\begin{abstract}
The impact of exposure to media representations of aggressive, attractive, female protagonists on audiences' gender role expectations for women was explored through a laboratory experiment with 122 undergraduates from a large university on the west coast of the United States. Participants viewed a segment of a major Hollywood motion picture that featured a female protagonist who was either highly attractive or less attractive and either highly aggressive or not aggressive. Viewing clips featuring a female protagonist who was both aggressive and stereotypically attractive led to greater endorsement of stereotypically feminine and stereotypically masculine gender role expectations for women. The effect on endorsement of stereotypically masculine expectations was partially mediated by the perception that the protagonist was a good role model for women. Although women endorsed both feminine and masculine gender role expectations for women more strongly than men, the effects of exposure to aggressive, attractive, female protagonists were similar for both male and female participants. Results are discussed in terms of gender stereotype activation and superwoman expectations for women.
\end{abstract}

Keywords Media effects · Aggression · Gender roles · Stereotyping

L. D. Taylor $(\bowtie) \cdot$ T. Setters

Communication Department, University of California, Davis,

One Shields Avenue,

Davis, CA 95616, USA

e-mail: lartaylor@ucdavis.edu

\section{Introduction}

Recently, researchers have noted the emergence of aggressive female protagonists on television and in the movies (Greenwood 2007) such as Kate Beckett of Castle, Echo of Dollhouse, Beatrix Kiddo from Kill Bill, and Jane Smith of Mr. \& Mrs. Smith. Although this trend has been observed and commented on primarily in the United States, U.S. media influences media content in many other countries (Bagdikian 2004). In addition to embodying stereotypically masculine traits of aggression and assertiveness, many of these protagonists also conform to stereotypical conceptions of female beauty. Some researchers have characterized these aggressive female protagonists as counter-stereotypical (Greenwood 2007); in light of the importance of physical appearance for such figures, it may be more accurate to characterize them as both challenging and reinforcing gender stereotypes. At least one cultural historian has argued that these aggressive female protagonists have long been a feature of American popular culture and essentially serve to reinforce stereotypes and role expectations about women (Inness 1999). Applying notions of priming and spreading activation as well as research on the influence of physical attractiveness on impression formation to the question, the present study sought to examine the impact of exposure to these stereotypically attractive, aggressive, female protagonists on gender role expectations for women. In a laboratory experiment, college undergraduates from a large university on the U.S. West coast viewed a film clip featuring a female protagonist who was stereotypically attractive or not and physically aggressive or not before completing measures of gender role expectations for women. 


\section{Media Effects on Gender Stereotyping}

Relatively little research has explored the impact of exposure to attractive, aggressive, female protagonists in the media. One notable exception was an investigation into whether these attractive female protagonists caused an increase in aggression among college-aged female viewers in the U.S.; they did (Greenwood 2007). Other effects, however, should also be considered. Past research has demonstrated that mediated depictions of gender stereotypical or counter-stereotypical behavior can affect the beliefs and expectations of viewers. Viewing television programs in which gender and sexual stereotypes are depicted has been shown to result in greater endorsement of depicted stereotypes in U.S. college- and high school-age samples (Ward 2002; Ward and Friedman 2006; Ward et al. 2005). This endorsement increases with habitual viewing of programming containing stereotypical depictions of gender roles, but can also be increased at least temporarily based on a single, brief, viewing experience (Ward 2002; Ward and Friedman 2006). These effects are not limited by media consumers' age or gender; a recent meta-analysis revealed a link between media exposure and endorsement of gender stereotypes for both male and female children and adults observed in studies that employed both survey and experimental methods (Oppliger 2007).

Nor are the effects of stereotype representations limited to the depicted stereotypes; viewing representations of one stereotype or a stereotype in one domain can result in endorsement of gender stereotypes in other domains. Unless otherwise indicated, the research cited here was conducted in the U.S. In one series of experiments, watching commercials that depicted women as stereotypically appearance- and consumption-oriented caused the activation of stereotypes of women as less capable at math among college students; this activation in turn caused women to express diminished interest in math-related careers (Davies et al. 2002). In another study, activation of the stereotype of women as appearance-oriented caused college-age women to be less likely to select a leadership role for themselves in a problem-solving task (Davies et al. 2005). Viewing depictions of stereotypically attractive protagonists may function in a similar fashion, leading to the endorsement of stereotypes in other, non-appearance domains. Inasmuch as physical attractiveness activates endorsement of gender stereotypes, viewing depictions of an attractive, aggressive, female protagonist may produce effects that go beyond increased aggression (Greenwood 2007). Although the protagonist's aggression may activate counter-stereotypical thoughts, her attractiveness may simultaneously activate stereotypical thoughts.

One type of cognition influenced by exposure to stereotypical media content is gender role expectations
(GRE), or those behaviors and attitudes expected of or held as a standard for members of a particular gender. Such expectations emerge early. Kindergarteners in one study showed strong tendencies to expect men and women to behave in ways consistent with existing gender stereotypes; these expectations also extended to their future, mature selves (Durkin and Nugent 1998). Gender role expectations are learned from many sources, including popular media content. Katz and Boswell (1986) found that media influenced gender role expectations more strongly than did parents or peers. Even brief exposures to stereotypical representations in the media have been shown to affect GRE, increasing the endorsement of stereotypical expectations for women (Lafky et al. 1996; Tan 1979).

The modeling of seemingly conflicting roles (i.e. stereotypically feminine beauty and stereotypically masculine aggression) by women may also affect the GRE of viewers. One study explored the impact of exposure to such conflicting gender role expectations in real life; girls who perceived their school environments as endorsing conflicting gender roles (e.g. both traditionally feminine and traditionally masculine roles for women) were more likely to subscribe to a 'superwoman' ideal themselves (Mensinger et al. 2007). This superwoman ideal refers to the notion that women should excel both in traditionally feminine domains (e.g. nurturance, physical beauty) and in traditionally masculine domains (e.g. assertiveness, corporate success) (Hart and Kenny 1997; Mensinger et al. 2007).

\section{Priming}

There are theoretical reasons to expect that even relatively brief exposure to an aggressive, attractive, female protagonist may affect the GRE of viewers at least temporarily. Priming occurs when some element of the environment, including the media environment, activates related cognitions, including thoughts, beliefs, or expectations, making those cognitions more likely to be used in subsequent decision-making (Roskos-Ewoldsen et al. 2009). Such priming effects explain how brief, experimental exposures to stereotypical content are able to increase stereotype endorsement (Lafky et al. 1996; Tan 1979). Past research has documented that violent media content primes aggressive cognitions (Bushman 1998; Farrar and Krcmar 2006; Josephson 1987; Meier et al. 2007), and exposure to images of stereotypically attractive women primes cognitions pertaining to standards of attractiveness among college students (Aubrey and Taylor 2009; Henderson-King et al. 2001). Effects of exposure to aggressive, attractive heroines may extend beyond effects on aggression and attractiveness, however, through the process of spreading activation. 
Spreading activation occurs when an element or node of a cognitive network becomes activated through priming, and cognitions that are linked to that activated cognition through associative pathways are also activated. Past research has shown, for example, that the activation of racial categories can lead to the activation of cognitions pertaining to topics stereotypically associated with that those categories; activating cognitions pertaining to crime have been shown to result in increased accessibility of cognitions relating to Blackness and vice versa (Dixon and Azocar 2007; Valentino 1999). It is also likely that spreading activation explains how exposure to one stereotype results in the endorsement of other stereotypes of members of the same gender; the various stereotypes are all linked associatively in the minds of viewers.

When considering the likely effects of exposure to attractive, aggressive, mediated women, it may be profitable to initially consider the likely effects of each element of those models independently. Spreading activation suggests likely consequences of exposure to mediated representations of stereotypically attractive women beyond activation of standards of attractiveness. Specifically, exposure to women embodying feminine beauty ideals may lead to increased endorsement of stereotypical expectations for women. Appearance-related stereotypes of women and girls tend to be among the most prevalent gender stereotypes in the U.S., even among children (Miller et al. 2009). Viewing women who physically represent a feminine ideal (as currently culturally defined) was therefore expected to lead to the activation of closely related constructs through a process of spreading activation. Inasmuch as stereotypical expectations of feminine beauty (i.e. women should be physically beautiful) are closely associated with other stereotypical expectations of feminine character or behavior (e.g. women should be supportive, women should be nurturing), activation of the former is likely to result in endorsement of the latter.

Hypothesis 1: Those who watch media depictions of an attractive female protagonist will endorse more stereotypically feminine gender role expectations for women than will those who watch depictions of a less attractive female protagonist.

Inasmuch as aggression is a trait stereotypically associated with men, it is likely that activating aggressive cognitions lead to increased accessibility of other stereotypically masculine traits such as assertiveness or competitiveness. Viewing women behaving in a fashion that is aggressive and assertive may activate cognitions consistent with such behavior, such as expectations that women behave in a more stereotypically masculine fashion. It was therefore expected that viewing an aggressive female protagonist would result in greater endorsement of counter-stereotypical expectations for women.

It should be noted, however, that this hypothesis is at least somewhat problematic. Contact with an individual who displays traits counter-stereotypical to her or his group sometimes alters perceptions of the group (Pratto and Bargh 1991), but often does not; in such cases, the individual exemplar is regarded as atypical of the group, and her traits are not applied to stereotypes about that group (Wilder 1984). This research, however, has focused on perceptions of the characteristics of members of stereotyped groups rather than expectations for members of that group. Expectations may be more akin to ideals or standards of judgment than to perceptions of characteristics. Viewing an aggressive, successful woman may not be likely to cause perceptions that women in general are aggressive but still be likely to cause the perception that women can be effectively aggressive, and, inasmuch as this is depicted as a desirable trait, should be. This reflects Hamburger's (1994) observation that a contact with a single stereotype disconfirming individual can affect group dispersion, if not the content of group stereotypes.

Hypothesis 2: Those who view media depictions of an aggressive female protagonist will endorse more stereotypically masculine gender roles for women than those who view depictions of a non-aggressive female protagonist.

These hypothesized effects may also be tempered by perceptions of or responses to the protagonists whose behavior is expected to drive them. Greenwood (2007) observed that the impact of exposure to aggressive female protagonists was largely limited to women who viewed those protagonists' behavior as worthy of emulation. It is possible that the degree to which modeled behavior activates various gender role expectations, either stereotypical or counter-stereotypical, will be limited in a similar way. This is particularly likely because gender role expectations reflect what women ought to do or be. If women viewing a violent protagonist perceive that protagonist to be an inappropriate role model for whatever reason, then they may actively reject the cognitions that would otherwise result in the activation of stereotypically masculine expectations for women.

One possible moderating factor is physical beauty; attractiveness of the aggressive protagonist may signal the appropriateness (or inappropriateness) of that protagonist as a role model, and therefore the appropriateness (or inappropriateness) of the aggressive behavior. Physical attractiveness has been demonstrated to function as a cue for judgments of a wide range of traits; attractive individuals are judged to be more capable, skilled, 
intelligent, and socially skilled (Asch 1946; Dion et al. 1972; Eagly et al. 1991). In evaluations of unknown politicians based on images alone, for example, more attractive individuals have been shown to be perceived as more competent, trustworthy, and qualified, and to have better leadership potential, than less attractive individuals (Surawski and Ossoff 2006).

It is therefore hypothesized that:

Hypothesis 3: Exposure to an attractive, aggressive, female protagonist will result in greater endorsement of stereotypically masculine gender role norms for women than exposure to a less attractive, aggressive, female protagonist.

Such a halo effect may play an important role in shaping the effects of viewing attractive, aggressive, female protagonists in the media. Although aggression, especially by women, is often seen in a negative light, this perception is not uniform (Barber et al. 1999; Brown and Sumner 2006). Past research has demonstrated that women's aggression results in greater opprobrium than identical acts of aggression performed by men, but that bias is eliminated among individuals who endorse more egalitarian gender norms (Barber et al. 1999; Brown and Sumner 2006). Furthermore, when individuals show anger, an emotion often associated with and predictive of aggression, they are perceived as more competent and more worthy of elevated status (Tiedens 2001). Furthermore, individuals who express anger are perceived as relatively more 'tough' (Sinaceur and Tiedens 2005). Although aggression itself may be viewed negatively in general, it is possible that aggression may also be interpreted as an indicator of anger, competence, and worth. When aggression is undertaken by an individual who is physically attractive, the halo effect may result in more favorable interpretations of that aggression. In fact, past research has shown that evaluations of at least one televised aggressive heroine hinged largely on her physical appearance; men and women who found her more attractive expressed greater intentions to continue watching her program (Calvert et al. 2001). The aggression may become something to be emulated rather than something to be condemned. It was therefore hypothesized that:

Hypothesis 4: Attractive female protagonists will be perceived as more appropriate role models for women than less attractive female protagonists. This perception will mediate the effect of attractiveness viewing on endorsement of stereotypically masculine GRE for women.

It was also considered possible that men and women's endorsement of GRE for women might be affected differently by depictions of an attractive, aggressive, female protagonist. Gender role expectations for women held by women may differ from those held by men (Schein et al. 1989). Furthermore, past research has suggested that women and men perceive aggression by women differently (Graf et al. 2009). The role of gender was therefore investigated by controlling for gender in all analyses.

The current study was designed to test these hypotheses by exposing U.S. college undergraduates to only one type of female protagonist-aggressive and attractive, aggressive but less attractive, attractive but not aggressive, or neither attractive nor aggressive-and comparing the gender role expectations for women endorsed by those who watched different types of female protagonists. Specifically, it was expected that (H1) exposure to an attractive protagonist (regardless of aggression) would result in stronger endorsement of feminine GRE for women than exposure to a less attractive protagonist; (H2) exposure to an aggressive protagonist (regardless of attractiveness) would result in stronger endorsement of masculine GRE for women than exposure to a non-aggressive protagonist; and (H3) exposure to an attractive, aggressive, female protagonist would result in greater endorsement of masculine gender role norms for women than exposure to a less attractive, aggressive, female protagonist. It was further expected that $(\mathrm{H} 4)$ attractive protagonists would be perceived as better role models for women than less attractive protagonists, and this perception would explain, at least in part, how exposure to the attractive, aggressive protagonist increased endorsement of masculine GRE for women.

\section{Method}

\section{Participants}

Participants were 122 undergraduate students (65 female, or 54\%) at a large, U.S., West-coast university. Participants were recruited either from undergraduate courses in communication in exchange for a small amount of extra credit or from student residences in exchange for a candy bar. Participants ranged in age from 18 to 29 (women: 18$29, M=20.94, S D=2.08$; men: $18-24, M=21.00, S D=1.40$ ), and most self-identified as heterosexual $(n=107$ or $92 \%)$ and either Caucasian/White ( $n=57$ or $46 \%$ ) or Asian/AsianAmerican $(n=47$ or $38 \%)$. After arriving at the research site, participants read and signed informed consent documents, were randomly assigned to an experimental condition, and were given a packet containing study materials. A researcher asked participants not to talk and to turn off cell phones; in the rare instances when participants talked during the study, the request that they refrain from doing so was repeated. Participants first 
completed demographic measures and measures of regular media use, then watched the media clip appropriate to their condition in small groups $(n=1-5)$ before completing a measure of gender role expectations. After completing the study, participants were debriefed, thanked, and dismissed.

\section{Experimental Stimuli}

Stimulus clips were chosen to embody the key causal elements, specifically physical attractiveness of the female protagonist and physical aggression by that same protagonist. In order to control for degree of attractiveness within aggression, two clips, one featuring a high degree of aggression the other featuring no aggression on the part of the protagonist, were selected for each of two actresses, one of whom was stereotypically attractive (Angelina Jolie), the other of whom was less so (Kathy Bates). In the violence clips (from Tomb Raider and Primary Colors, respectively), the protagonist engaged in physical violence, exerted mastery in a difficult situation, used a firearm, and was successful in obtaining a goal. In the scene from Tomb Raider, the Jolie character is interrupted in her attempt to steal what appears to be an archaeological treasure by a homicidal android. She shoots it, kicks it, topples an obelisk onto it, and tears out its wiring until it stops functioning. In the clip from Primary Colors, the Bates character confronts a lawyer who may have committed fraud as part of a political attack on her employer; in the face of his denial, she physically assaults him and menaces him with a large handgun until he capitulates, confessing to his deceit. Although both violent characters are ostensibly 'good guys,' their aggression is not unambiguously virtuous or necessarily justified. One initiates the violence against an individual who may be innocent; the other acts in self-defense but precipitates the attack by apparently committing a crime. The violent protagonists are, however, unambiguously successful; aggression brings about success.

In the non-violent clips (from Changeling and Fried Green Tomatoes, respectively), the protagonist was passive and submissive. In Changeling, the Jolie character attempts to confront a police officer who has tried to pass off a strange boy as her kidnapped child. When the officer insists that she is mistaken, she becomes upset and raises her voice, but her anger quickly turns to tears and an apologetic, submissive tone; she leaves without his admitting the mistake. In Fried Green Tomatoes, the Bates character is rudely cut off and insulted as she exits a grocery store; when, all annoyed, she attempts to point out the ill manners of one of her belittlers, he is rudely dismissive, and she ends up appearing forlorn, helplessly grasping at her spilled groceries. Each of the four clips represented a single, intact scene and was between 4 and 6 min long. Each character portrayed by each actor was, both in the clip and the overall film, arguably one of the 'good guys,' that is, not a villain.

The key attributes of the clips' protagonists (i.e. physical attractiveness and aggression) were assessed as 24 individuals from the same population from which the experimental sample was drawn viewed and rated all four clips (mean age of judges was 20.17, $S D=2.17 ; 14$ were women, or $58 \%$ ). After viewing each clip, these judges indicated the degree to which the protagonist was attractive and aggressive on a 5 -point scale $(1=$ not at all, $5=$ extremely), as well as indicating whether they had ever seen the movie previously. The manipulation was tested by conducting a pair of two 2 (protagonist attractiveness) $\times 2$ (protagonist aggression) within-subjects ANOVAs. For perceived attractiveness, a significant effect of the attractiveness manipulation was observed, $F(1,23)=$ $106.49, p<.001$; neither the aggression manipulation nor the interaction was a significant predictor. Characters portrayed by Angelina Jolie were perceived as more physically attractive than those portrayed by Kathy Bates $(M=4.02$, $S D=.76$ and $M=1.85, S D=.72$, respectively). For perceived aggression, a significant effect of the aggression manipulation was observed, $F(1,23)=231.67, p<.001$; neither the attractiveness manipulation nor the interaction was a significant predictor. The protagonists in the aggressive clips were perceived as more aggressive than the protagonists in the non-aggressive clips $(M=3.62, S D=.60$ and $M=1.20$, $S D=.44$, respectively). There were differences in how familiar judges were with the movies from which the clips were drawn; significantly more judges had seen Tomb Raider $(n=12$ or $50 \%)$ than Primary Colors. $(n=4$ or $17 \%)$.

\section{Perceptions of the Protagonists}

Two key perceptions of the protagonist in each clip were measured. First, behavioral idealization was measured as participants expressed their agreement with the statement, "I believe the female character portrayed in the clip is a good role model for women" on a scale from 1 (strongly disagree) to 5 (strongly agree) $(M=2.90, S D=1.23)$. Second, perceptions of the female protagonist as physically attractive were assessed as participants were asked to rate the appearance of the protagonist on a scale from 1 (not at all attractive) to 10 (very attractive) $(M=5.66, S D=2.89)$. This 10-point scale was employed to reflect the common cultural approach to rating attractiveness on a 10-point scale (e.g. 1979 Bo Derek vehicle 10, popular web site hotornot.com).

\section{Gender Role Expectations}

Gender role expectations were assessed using a measure designed for the present study. Because the study hypotheses were based in part on the idea that activating a narrow set of 
cognitions about gender roles (e.g. stereotypes about women's ideal appearance, counter-stereotypical thoughts of female aggression) would lead to the activation of related but distinct gender role expectations (e.g. feminine and masculine GRE for women generally), we sought to develop a broad measure of GRE for women. This stands in contrast to studies that have focused on a narrow range of GRE, such as expectations for sexual behavior (Viki and Abrams 2002), the choice of clothing (Workman and Johnson 1994), or the performance of specific tasks (Durkin and Nugent 1998). Furthermore, past researchers have often conceptualized GRE as either traditional or non-traditional (e.g. Workman and Johnson 1994); however, research documenting the endorsement of a 'Superwoman' ideal suggests that both traditional/stereotypical and non-traditional/counter-stereotypical ideals for women can be endorsed simultaneously (Hart and Kenny 1997; Mensinger et al. 2007).

Drawing on Linville's (1985) work on self-roles, therefore, several roles women students were judged likely to see as important (e.g. student, worker, family member, friend) were selected. Statements about appropriate behavior for women in each of these roles were then constructed drawing on research pertaining to stereotypes of masculinity and femininity. This research has shown that women are stereotypically expected to be nurturing and oriented toward the well-being of others (see Etaugh and Folger 1998; see also Bem 1974) whereas men are expected to be calculating and ambitious (see King et al. 1991). The resulting statements reflected the belief that women should exhibit either stereotypically masculine traits such as assertiveness and an achievement orientation (e.g. "It is important for a woman to use the people in her social network as contacts to help her get ahead,") or stereotypically feminine traits, such as being nurturing and person oriented (e.g. "It is important for a woman to make significant efforts to emotionally bond with the people in her social network").

Twelve statements were employed in the study (see Appendix A for all 12 items). Participants responded to each item on a 5-point scale where $1=$ strongly disagree, $5=$ strongly agree. Responses to the 12 items were subjected to exploratory factor analysis; exploratory rather than confirmatory factor analysis was selected because it was unclear whether the relevant underlying constructs were those dealing with the roles of women or those dealing with stereotypically masculine or feminine expectations within a variety of roles. Three factors emerged, two of which were relevant to the present study and readily interpretable. The first of these was stereotypically feminine GRE for women (eigenvalue $=3.62$, $30.35 \%$ of variance explained), and included statements dealing with women being nurturing and focused on others in school, social, and familial roles. The second factor featured stereotypically masculine GRE for women (eigenvalue =
$1.91,15.93 \%$ of variance explained) and included statements emphasizing the importance of aggressive, assertive, and ambitious behavior in social and familial roles. The third factor contained a single item (eigenvalue $=1.11,9.27 \%$ of variance explained), and was not used in further analyses. Responses to the various items in each scale were averaged to form a 6-item measure of stereotypically feminine expectations for women $(M=3.75, S D=.55, \alpha=.79)$ and a 5 -item measure of stereotypically masculine expectations for women $(M=3.15, S D=.67, \alpha=.70)$. The two scales were also found to be positively correlated $(r=.27, p<.01)$. One participant who completed all other items failed to respond to one of the statements relating to stereotypically feminine GRE for women, resulting in one fewer participant for analyses involving that scale.

\section{Results}

First, descriptive statistics were calculated for all measures (see Table 1). A Chi-square analysis was also conducted that indicated the two most prominent ethnic groups (i.e. White and Asian/Asian-American) were each roughly equally represented across conditions.

Perceived attractiveness was then compared across conditions as a manipulation check. This was done as a 2 (participant gender) $\times 2$ (protagonist attractiveness) $\times 2$ (protagonist aggression) ANOVA was computed with perceived attractiveness of the protagonist as the dependent variable. The only significant predictor was for the attractiveness manipulation, $F(1,111)=201.65, p<.001$. The female protagonists in the 'attractive' condition (both portrayed by Angelina Jolie) were perceived as significantly more attractive than the characters in the 'less attractive' condition (both portrayed by Kathy Bates) $(M=7.80, S D=$ 1.76 and $M=3.23, S D=1.77$, respectively). There was no difference in perceived attractiveness between protagonists in the aggression condition relative to the non-aggression condition, nor was the interaction between conditions significant; attractiveness was successfully controlled by the experimental manipulation.

Hypotheses were tested though a MANOVA with attractive protagonist viewing, violent protagonist viewing, and viewer gender as factors and endorsement of masculine and feminine GRE for women as dependent variables. Follow-up analyses were conducted with ANOVA.

For the omnibus test, a main effect was observed for participant gender, Wilks' $F(3,109)=3.86, p<.01$, $\eta^{2}=.096$. Follow-up ANOVAs indicated a significant effect of gender on both endorsement of stereotypically feminine GRE, $F(1,111)=8.59, p<.01, \eta^{2}=.072$, and 
Table 1 Means and standard deviations of study variables relative to participant gender and experimental condition

\begin{tabular}{|c|c|c|c|c|c|c|c|c|}
\hline & \multicolumn{2}{|c|}{$\begin{array}{l}\text { Protagonist neither } \\
\text { attractive nor aggressive }\end{array}$} & \multicolumn{2}{|c|}{$\begin{array}{l}\text { Protagonist attractive, } \\
\text { not aggressive }\end{array}$} & \multicolumn{2}{|c|}{$\begin{array}{l}\text { Protagonist aggressive, } \\
\text { not attractive }\end{array}$} & \multicolumn{2}{|c|}{$\begin{array}{l}\text { Protagonist attractive } \\
\& \text { aggressive }\end{array}$} \\
\hline & $\begin{array}{l}\text { Male } \\
(n=10)\end{array}$ & $\begin{array}{l}\text { Female } \\
(n=22)\end{array}$ & $\begin{array}{l}\text { Male } \\
(n=12)\end{array}$ & $\begin{array}{l}\text { Female } \\
(n=16)\end{array}$ & $\begin{array}{l}\text { Male } \\
(n=12)\end{array}$ & $\begin{array}{l}\text { Female } \\
(n=14)\end{array}$ & $\begin{array}{l}\text { Male } \\
(n=21)\end{array}$ & $\begin{array}{l}\text { Female } \\
(n=15)\end{array}$ \\
\hline $\begin{array}{l}\text { Protagonist is a good role } \\
\text { model for women }\end{array}$ & $2.00_{\mathrm{a}}(.33)$ & $2.0 \mathrm{a}(.22)$ & $3.17_{\mathrm{ab}}(.30)$ & $3.25_{\mathrm{ab}}(.26)$ & $2.42_{\mathrm{ab}}(.30)$ & $2.50_{\mathrm{ab}}(.28)$ & $3.57_{\mathrm{b}}(.23)$ & $3.93_{\mathrm{b}}(.27)$ \\
\hline Protagonist attractiveness & $2.40_{\mathrm{a}}(.55)$ & $3.68_{\mathrm{a}}(.37)$ & $6.75_{\mathrm{b}}(.50)$ & $7.69_{\mathrm{b}}(.43)$ & $2.73_{\mathrm{a}}(.52)$ & $3.50_{\mathrm{a}}(.46)$ & $8.19_{\mathrm{b}}(.38)$ & $8.13_{\mathrm{b}}(.45)$ \\
\hline $\begin{array}{l}\text { Feminine gender role } \\
\text { expectations for women }\end{array}$ & $3.60(.16)$ & $3.81(.11)$ & $3.53(.15)$ & $3.84(.13)$ & $3.51(.15)$ & $3.65(.14)$ & $3.73(.11)$ & $4.38(.13)$ \\
\hline $\begin{array}{l}\text { Masculine gender role } \\
\text { expectations for women }\end{array}$ & $2.74(.19)$ & $3.27(.13)$ & $2.93(.18)$ & $3.12(.15)$ & $2.98(.18)$ & $2.80(.16)$ & $3.32(.13)$ & $3.77(.16)$ \\
\hline
\end{tabular}

Each cell contains the cell mean; quantities in parentheses are standard deviations. For "Protagonist is a good role model for women," as well as individual items in Gender Role Expectations measures, scale range was 1 (strongly disagree) - 5 (strongly agree); for protagonist attractiveness, scale range was 1 (not at all attractive) - 10 (very attractive). Means in the same row with different subscripts are significantly different at $p<.05$

stereotypically masculine GRE, $F(1,111)=4.07, p<.05$, $\eta^{2}=.035$. In each case, this was reflective of greater endorsement of GRE among female than among male participants (see Table 2). Gender did not affect perception of the protagonist as an appropriate role model.

A main effect was also observed for the attractive protagonist viewing manipulation, $F(3,109)=16.01$, $p<.001, \eta^{2}=.31$. Follow-up ANOVAs indicated a significant effect of condition on both endorsement of stereotypically feminine GRE, $F(1,111)=5.02, p<.05, \eta^{2}=.043$, and stereotypically masculine GRE, $F(1,111)=7.90, p<.01$, $\eta^{2}=.066$. In each case, this was reflective of greater endorsement of GRE among those who viewed the more stereotypically attractive protagonist compared to the less stereotypically attractive protagonist (see Table 3). Attractive protagonist viewing also affected the perception of the protagonist as an appropriate role model, $F(1,111)=$ 38.01, $p<.001, \eta^{2}=.26$. Participants perceived the more

Table 2 Perceived attractiveness and appropriateness of movie protagonist as a role model and endorsement of GRE for women among female and male study participants

\begin{tabular}{lll}
\hline & $\begin{array}{l}\text { Women } \\
(N=65)\end{array}$ & $\begin{array}{l}\text { Men } \\
(N=54)\end{array}$ \\
\hline $\begin{array}{l}\text { Perceived physical attractiveness } \\
\text { of female movie protagonist }\end{array}$ & $5.64(2.90)$ & $5.70(2.92)$ \\
$\begin{array}{c}\text { Endorsement of female movie } \\
\text { protagonist as a good role model }\end{array}$ & $2.86(1.35)$ & $2.96(1.10)$ \\
$\begin{array}{l}\text { Endorsement of stereotypically } \\
\text { feminine gender role } \\
\text { expectations for women }\end{array}$ & $3.88_{\mathrm{a}}(.065)$ & $3.59_{\mathrm{b}}(.074)$ \\
$\begin{array}{l}\text { Endorsement of stereotypically } \\
\text { masculine gender role } \\
\text { expectations for women }\end{array}$ & $3.24_{\mathrm{a}}(.078)$ & $3.00_{\mathrm{b}}(.088)$ \\
\hline
\end{tabular}

Quantities in parentheses represent standard errors. Means in the same row with differing subscripts are significantly different at $\alpha=.05$, two-tailed attractive protagonists as better role models than the less attractive protagonists.

This main effect of exposure to the attractive protagonist was qualified, however, by an interaction between violent protagonist viewing and attractive protagonist viewing that was also significant, Wilks' $F(3,109)=3.84, p<.01$, $\eta^{2}=.096$. Once again, this interaction significantly affected endorsement of both endorsement of stereotypically feminine GRE, $F(1,111)=5.00, p<.05, \eta^{2}=.043$, and stereotypically masculine GRE, $F(1,111)=8.03, p<.01$, $\eta^{2}=.067$. Post-hoc testing indicated that for endorsement of stereotypically feminine GRE for women, participants who viewed the violent, attractive protagonist endorsed feminine GRE significantly more strongly than participants who viewed the violent, less stereotypically attractive protagonist; those who viewed either non-violent protagonist were significantly different from neither. For endorsement of stereotypically masculine GRE for women, post-hoc testing revealed that participants who viewed the attractive, aggressive protagonist endorsed more stereotypically masculine GRE for women than participants who viewed any other protagonist. The interaction was not a significant predictor of perceptions of the protagonist as a good role model, $F(1,111)=.10$, n.s.

The three-way interaction among gender, attractive protagonist viewing, and aggressive protagonist viewing was not significant, Wilks' $F(3,109)=1.42$, n.s.

\section{Mediation}

The hypothesis that the effect of exposure to an attractive, aggressive protagonist on endorsement of stereotypically masculine norms would be mediated by perceptions of the protagonist as worthy of emulation was tested using the bootstrapping technique employing 
Table 3 Endorsement of GRE for women after viewing a film representation of a protagonist who was stereotypically attractive or not and aggressive or not

\begin{tabular}{|c|c|c|c|c|}
\hline & $\begin{array}{l}\text { Neither attractive } \\
\text { nor aggressive }\end{array}$ & $\begin{array}{l}\text { Attractive, but } \\
\text { not aggressive }\end{array}$ & $\begin{array}{l}\text { Not attractive, } \\
\text { but aggressive }\end{array}$ & $\begin{array}{l}\text { Attractive \& } \\
\text { aggressive }\end{array}$ \\
\hline $\begin{array}{l}\text { Feminine gender role expectations } \\
\text { for women }\end{array}$ & $3.69_{\mathrm{a} \mathrm{b}}(.10)$ & $3.69_{\mathrm{a} \mathrm{b}}(.10)$ & $3.56_{\mathrm{a}}(.10)$ & $4.00_{\mathrm{b}}(.087)$ \\
\hline $\begin{array}{l}\text { Masculine gender role expectations } \\
\text { for women }\end{array}$ & $3.03_{\mathrm{a}}(.12)$ & $3.03_{\mathrm{a}}(.11)$ & $2.88_{\mathrm{a}}(.12)$ & $3.55_{\mathrm{b}}(.10)$ \\
\hline Protagonist is a good role model & $2.02_{\mathrm{b}}(.21)$ & $3.21_{\mathrm{a}}(.20)$ & $2.44_{\mathrm{b}}(.21)$ & $3.75_{\mathrm{a}}(.18)$ \\
\hline
\end{tabular}

Quantities in parentheses represent standard errors. Means in the same row with differing subscripts are significantly different at $\alpha=.05$, two-tailed Participant gender was included in the analysis and exerted a main effect on GRE as reported in Table 2; no effect of gender through interaction with movie type was observed, however; participant gender was therefore omitted from the table

Preacher and Hayes' (2004) macro for SPSS. Because post-hoc tests indicated a significant difference between the violent/attractive clip and all other clips, and no differences between other clips, the meditation analysis explored whether that particular effect was mediated by perceptions of the protagonist as a good role model. H4 was supported, as the indirect effect was significant (.18; CI: .060-.32). As the $95 \%$ confidence interval does not include zero, the null hypothesis that the indirect effect is zero can be rejected.

Although not indicated by the above hypotheses, a mediation analysis was also conducted employing the same procedure to explore whether perception of the protagonist as a role model mediated the relationship between viewing an attractive, aggressive protagonist and endorsement of stereotypically feminine norms for women. The mediated path was not significant.

\section{Discussion}

In the current study, the effects of exposure to an attractive and aggressive female protagonist on gender role expectations for women were explored. Findings suggested that attractiveness and aggressiveness of a female protagonist affected these expectations, increasing the degree to which both women and men expected women to fulfill both stereotypical and counterstereotypical roles. These effects, however, occurred by different processes, suggesting that aggression and attractiveness interact in relatively complex ways.

Among participants in the present study, women generally tended to have higher expectations of women than men; female participants endorsed both more stereotypically feminine and more stereotypically masculine expectations for women than did male participants. This differential endorsement may reflect differences in the cognitive process of responding to statements about ideal women arising due to women's inclusion of their own behaviors and traits. A more likely explanation, however, is that women have higher standards for other women than do men, much as women tend to endorse a thinner body ideal for women than do men (Fallon and Rozin 1985). That this was observed for both stereotypically feminine and stereotypically masculine GRE for women may be interpreted as consistent with past research on "superwoman" expectations. Women expect that women should excel in a wide variety of domains. This may be problematic, as past research has found endorsement of superwoman ideals to be associated with disordered eating (Hart and Kenny 1997; Thornton et al. 1991).

Exposure to an attractive female protagonist resulted in increased endorsement of stereotypically feminine gender role expectations for women. This effect was moderated, however, by protagonist aggression; viewing the attractive, aggressive, female protagonist produced an increase in endorsement of stereotypically feminine GRE for women. This is consistent with a spreading activation explanation, in which stereotypical attractiveness is linked to such expectations and activating one leads to the activation of the other. Exposure to an attractive protagonist was expected to produce this effect, particularly in comparison to exposure to a less attractive, aggressive protagonist, who would be perceived as not embodying any stereotypically feminine traits.

It is less clear why the attractive, non-aggressive character did not lead to greater endorsement of stereotypically feminine GRE for women, given the absence of stereotypically masculine cues. One explanation might be that her aggression rendered the attractive, aggressive protagonist a more appealing role model than her essentially passive, non-aggressive counterpart. In this account, it is not, perhaps, the aggression that is the key consideration, but rather the success or effectiveness of the protagonist. Interestingly, the observed effect was independent of 
judgments pertaining to the appropriateness of the attractive protagonist as an appropriate role model. Although attractive heroines were perceived as better role models in general, this perception did not mediate the influence of exposure to such heroines on the activation and endorsement of stereotypically feminine GRE for women.

Alternately, some characteristic of the content other than the presence of a stereotypically physically attractive woman may have activated additional stereotypes for women or in some other way affected perception of the protagonist. Although there was no difference in attractiveness between the two characters portrayed by Jolie, the aggressive character may have been seen as more provocatively attired (midriff-baring tank top, shorts, and boots) than the non-aggressive character (loose-fitting, tea-length, short-sleeved dress). Interpretations of the aggressive character's mode of dress as sexualized may have contributed to activation of stereotypically feminine gender role expectations for women. Alternately, the difference in effectiveness between the two characters may have contributed to the observed differences. The success of the protagonist in Tomb Raider stands in sharp contrast to the failure of the protagonist in Changeling. Although neither was perceived as a better role model than the other, the success of one may have made her appealing characteristics (i.e., feminine attractiveness) more appealing yet.

Watching a female protagonist behave aggressively was found to activate stereotypically masculine gender role expectations for women, but only when the protagonist was stereotypically physically attractive. This is again supportive of a spreading activation response to GRE endorsement; one counter-stereotypical behavior was depicted (i.e. aggression or violence), but others were activated in turn (e.g. career ambition). The restriction of this effect to depictions of aggression by a stereotypically attractive model, however, suggests a more complex process than simple spreading activation. The results of the mediation analysis offer insight into this process, as they indicate that an evaluation of the appropriateness of the observed behavior is made as part of the activation process. Physical attractiveness is seemingly used as a signal of that appropriateness; violence by a woman is only deemed an appropriate signal for the activation of expectations for women in general if that woman is also physically attractive. This is also reflected in the fact that attractive protagonists were judged better role models than less attractive protagonists. Price and Tewksbury (1997) referred to a similar process as an 'applicability effect' in which media content signaled the appropriateness or inappropriateness of cognitions within the mind of the viewer as distinct from the 'accessibility effect' described above as priming. In the applicability account, not all media content activates all potentially related cognitions. Instead, only relevant or applicable cognitions are activated.

This difference in process between activation of stereotypically feminine and stereotypically masculine GRE may reflect differences in the nature of the expectations being activated. Activation of traditionally feminine GRE upon exposure to a segment featuring a stereotypically attractive female may be more automatic because those expectations are consistent with predominant gender stereotypes. Frequent, even habitual activation of stereotypically feminine expectations for women may result in a chronic state of semiactivation, making the stereotypic GRE more readily accessible. Activation of what are essentially counter-stereotypical expectations may be more difficult. Whether this is the case could be explored in future research by measuring the accessibility of a range of GRE for women among participants and examining whether those with highly accessible stereotypically feminine GRE respond differently than those for whom the same expectations are less accessible.

Attractiveness played a key role in predicting whether a protagonist was considered an appropriate role model for women. This is consistent with the notion that physical beauty signals a host of desirable traits or characteristics (Asch 1946; Dion et al. 1972; Eagly et al. 1991). This seemed to function as a partial determinant of the effects observed in the present study rather than an effect in and of itself. This may, therefore, suggest a potential point of interference for the effects observed. If the link between physical attractiveness, or conformity to a particular standard of physical beauty, and other positive attributes can be uncoupled, then attractive, aggressive protagonists may seem a somewhat less appropriate role model. Expectations would then be less affected by viewing depictions of such protagonists.

Aggressive protagonists were also considered better role models than less aggressive role models. This was true regardless of the physical attractiveness of the characters, and is therefore not merely a case of interpreting questionable moral behavior in a positive light due to a halo effect. This effect of protagonist aggression on the perception of that protagonist's worth as a role model seems to run counter to past findings indicating disapproval of aggression in general, particularly when undertaken by women (Barber et al. 1999). The observed perception may reflect the success achieved through aggression-individuals who achieve goals or who win may be perceived as more desirable role models regardless of whether they use aggression. Both aggressive characters triumphed; both non-aggressive characters 
were frustrated. The effect may therefore reflect not a fundamental interpretation of aggression as a desirable trait for women, but rather an orientation toward desirable outcomes. Assertiveness and confidence accompanied the aggression in the clips employed in the present study; it may also be one of these traits, rather than aggression itself, that led to a greater tendency to perceive aggressive protagonists as appropriate role models. It should also be noted that justified aggression is perceived as less severe or problematic than unjustified aggression (Moore and Cockerton 1996), but can also produce stronger effects (Meyer 1972). Although Jolie's character acted in self-defense and Bates's instigated the aggression, both acts of aggression are depicted as essentially moral rather than cruel or arbitrary. Of note, there was no interaction between protagonist aggression and appearance conditions; the results did not reflect a case of a single character being perceived as a better role model than any other character. Future research should explore the impact of varied aspects of aggression systematically. Aggressive, attractive protagonists may be less influential if their aggression is unjustified, cruel or graphic, or unsuccessful; if the aggression is immoral or does not result in a valued outcome, its instigator is unlikely to be perceived as a good role model. Such investigations are of particular import given the importance of behavioral approbation as a mediating factor in the impact of exposure to aggressive, attractive protagonists on endorsement of stereotypically masculine GRE for women.

It should also be noted that these findings are limited to a particular type of gender-related cognitions-GRE may function differently from other types of gender stereotypes. After all, GRE refer to what ought to be rather than what generally or universally is.

These findings, viewed collectively, paint a somewhat troubling picture for the impact of what may initially seem to be stereotype-busting characters in the media. Initially, elements of the findings may seem promising increased endorsement of stereotypically masculine GRE for women seems to indicate a broadening of appropriate gender roles for women, and endorsement of an aggressive female protagonist as an appropriate role model seems to indicate a reduction in the double standard that has been applied to interpretations of aggression (Barber et al. 1999; Brown and Sumner 2006). However, it should be noted that this increase in endorsement of masculine GRE was accompanied by an increase in endorsement of stereotypically feminine GRE. Exposure to attractive, aggressive female characters actually increases expectations on women, including potentially inconsistent roles - after viewing, women were expected to be both more independent and ambitious and more socially connected and nurturing. These increased expectations for women occurred not only among men, but among women as well, suggesting that women's expectations of themselves are likely affected. Such elevated expectations are likely to increase both the experience of stress and behaviors undertaken to manage stress, even when such behaviors may be harmful (e.g. disordered eating) (Hart and Kenny 1997).

There are limitations to the study, the foremost being that, as with any experimental study employing real-world media content, the experimental stimuli are specific, complex texts whose generalizability is limited. In addition, the study was limited to a relatively brief exposure rather than an entire film. Of course, if these effects can be induced based on such a brief exposure, it is likely that full movie that shows the attractive, aggressive protagonist rewarded for her aggression would result in stronger effects rather than weaker. Baseline exposure to other types of media content featuring attractive, aggressive protagonists, such as on television, was not assessed.

Another limitation lies with the sample employed. Although ethnically diverse, the sample was somewhat limited in its diversity as a large minority of participants identified as Asian or Asian-American. It is possible that these participants' responses to the film were informed by distinct cultural narratives about and conceptualizations of feminine appearance and appropriate feminine behavior. This limitation is qualified, however. Asianand Asian-American participants were roughly equally represented in each experimental condition and among male and female participants. Furthermore, although more specific details about cultural identification were not collected, students who identify as Asian or AsianAmerican at the university at which the study was collected frequently come from families that have been in the U.S. for generations with roots in diverse cultures (e.g., Chinese, South Korean, Vietnamese, Hmong). Nevertheless, future research might profitably seek out samples with greater representation from groups with divergent beauty standards or ideals.

In spite of these limitations, the present research at least strongly suggests that exposure to depictions of attractive, aggressive, female protagonists can affect gender role expectations for women among viewers. Furthermore, this effect seems to include both stereotypically feminine and masculine expectations, indicating higher overall expectations for women. Viewing these depictions can change the way both men and women think about who women ought to be.

Open Access This article is distributed under the terms of the Creative Commons Attribution Noncommercial License which permits any noncommercial use, distribution, and reproduction in any medium, provided the original author(s) and source are credited. 


\section{Appendix A}

Items for measuring gender role expectations (GRE) for women

Stereotypically masculine GRE

It is important for a woman to:

- use the people in her social network as contacts to help her get ahead.

- know it is more important to give "practical advice" rather than emotional comfort to a troubled female friend.

- prefer to do most things on her own with little input from her parents and family.

- abide by the motto, "All is fair in love and war."

- do everything it takes to climb the hierarchical ladder in her chosen career.

- actively pursue an education and aim for top academic honors. (loaded on a third factor; not included in analysis)
Stereotypically feminine GRE

It is important for a woman to:

- make significant efforts to emotionally bond with the people in her social network.

- "be there" emotionally for her female friends.

- spend much of her free time catching up with friends and family.

- remember that kindness and compassion are necessary ingredients of good female leadership.

- set significant time aside as a student to help fellow students understand the course material if she "gets it" and they do not.

- be sympathetic and tender while working as a community service volunteer.

\section{References}

Asch, S. E. (1946). Forming impressions of personality. Journal of Abnormal and Social Psychology, 41, 258-290. doi:10.1037/ h0055756.

Aubrey, J. S., \& Taylor, L. D. (2009). The role of lad magazines in priming men's chronic and temporary appearance-related schemata: An investigation of longitudinal and experimental findings. Human Communication Research, 35, 28-58. doi:10.1111/j.14682958.2008.01337.x.

Bagdikian, B. H. (2004). The new media monopoly. Boston: Beacon.

Barber, M. E., Foley, L. A., \& Jones, R. (1999). Evaluations of aggressive women: The effects of gender, socioeconomic status, and level of aggression. Violence and Victims, 14, 353-363.

Bem, S. L. (1974). The measurement of psychological androgyny. Journal of Consulting and Clinical Psychology, 42, 155-162. doi:10.1037/h0036215.

Brown, T. J., \& Sumner, K. E. (2006). Perceptions and punishments of workplace aggression: The role of aggression content, context, and perceiver variables. Journal of Applied Social Psychology, 36, 2509-2531. doi:10.1111/j.0021-9029.2006.00115.x.

Bushman, B. J. (1998). Priming effects of media violence on the accessibility of aggressive constructs in memory. Personality and Social Psychology Bulletin, 24, 537-545. doi:10.1177/ 0146167298245009 .

Calvert, S. L., Kondla, T. A., Ertel, K. A., \& Meisel, D. S. (2001). Yound adults' perceptions and memories of a televised woman hero. Sex Roles, 45, 31-52. doi:10.1023/A:1013008300927.

Davies, P. G., Spencer, S. J., Quinn, D. M., \& Gerhardstein, R. (2002). Consuming images: How television commercials that elicit stereotype threat can restrain women academically and professionally. Personality and Social Psychology Bulletin, 28, 16151628. doi: $10.1177 / 014616702237644$.

Davies, P. G., Spencer, S. J., \& Steele, C. M. (2005). Clearing the air: Identity safety moderates the effects of stereotype threat on women's leadership aspirations. Journal of Personality and Social Psychology, 88, 276-287. doi:10.1037/0022-3514.88.2.276.

Dion, K., Berscheid, E., \& Walster, E. (1972). What is beautiful is good. Journal of Personality and Social Psychology, 24, 285290. doi:10.1037/h0033731.
Dixon, T. L., \& Azocar, C. L. (2007). Priming crime and activating blackness: Understanding the psychological impact of the overrepresentation of blacks as lawbreakers on television news. The Journal of Communication, 57, 229-253. doi:10.1111/ j.1460-2466.2007.00341.x.

Durkin, K., \& Nugent, B. (1998). Kindergarten children's gender-role expectations for television actors. Sex Roles, 38, 387-402. doi:10.1023/A:1018705805012.

Eagly, A. H., Ashmore, R. D., Makhijani, M. G., \& Longo, L. C. (1991). What is beautiful is good, but...: A meta-analytic review of research on the physical attractiveness stereotype. Psychological Bulletin, 110, 109-128. doi:10.1037/0033-2909. 110.1.109.

Etaugh, C., \& Folger, D. (1998). Perceptions of parents whose work and parenting behaviors deviate from role expectations. Sex Roles, 39, 215-223. doi:10.1023/A:1018850404838.

Fallon, A. E., \& Rozin, P. (1985). Sex differences in perceptions of desirable body shape. Journal of Abnormal Psychology, 94, 102 105. doi:10.1037/0021-843X.94.1.102.

Farrar, K., \& Krcmar, M. (2006). Measuring state and trait aggression: A short, cautionary tale. Media Psychology, 8, 127-138. doi:10.1207/s1532785xmep0802 4.

Graf, R. G., Yabko, B. A., \& Christensen, P. N. (2009). Gender effects in the assessment of technical fouls among high school basketball officials and collegiate proxies. Journal of Sport Behavior, 32, 175-188.

Greenwood, D. N. (2007). Are female action heroes risky role models? Character identification, idealization, and viewer aggression. Sex Roles, 57, 725-732. doi:10.1007/s11199-007-9290-5.

Hamburger, Y. (1994). The contact hypothesis reconsidered: Effects of the atypical outgroup member on the outgroup stereotype. Basic and Applied Social Psychology, 15, 339-358. doi:10.1207/ s15324834basp1503_8.

Hart, K., \& Kenny, M. E. (1997). Adherence to the Super Woman ideal and eating disorder symptoms among college women. Sex Roles, 36, 461-478. doi:10.1007/BF02766684.

Henderson-King, D., Henderson-King, E., \& Hoffmann, L. (2001). Media images and women's self-evaluations: Social context and importance of attractiveness as moderators. Personality and Social Psychology Bulletin, 27, 1407-1416. doi:10.1177/ 01461672012711002 . 
Inness, S. A. (1999). Tough girls: Women warriors and wonder women in popular culture. Philadelphia: University of Pennsylvania Press.

Josephson, W. L. (1987). Television violence and children's aggression: Testing the priming, social script, and disinhibition predictions. Journal of Personality and Social Psychology, 53, 882-890. doi:10.1037/0022-3514.53.5.882.

Katz, P. A., \& Boswell, S. (1986). Flexibility and traditionality in children's gender roles. Genetic, Social, and General Psychology Monographs, 112, 103-147.

King, W. C., Jr., Miles, E. W., \& Kniska, J. (1991). Boys will be boys (and girls will be girls): The attribution of gender role stereotypes in a gaming situation. Sex Roles, 25, 607-623. doi:10.1007/ BF00289567.

Lafky, S., Duffy, M., \& Berkowitz, D. (1996). Looking though gendered lenses: Female stereotyping in advertisements and gender role expectations. Journalism and Mass Communication Quarterly, 73, 379-388.

Linville, P. (1985). Self-complexity and affective extremity: Don't put all your eggs in one cognitive basket. Social Cognition, 3, 94-120.

Meier, B. P., Robinson, M. D., \& Wilkowski, B. M. (2007). Aggressive primes activate hostile information in memory: Who is most susceptible? Basic and Applied Social Psychology, 29, 23-34. doi:10.1080/01973530701330900.

Mensinger, J. L., Bonifazi, D., \& LaRosa, J. (2007). Perceived gender role prescriptions in schools, the superwoman ideal, and disordered eating among adolescent girls. Sex Roles, 57, 557568. doi:10.1007/s11199-007-9281-6.

Meyer, T. P. (1972). Effects of viewing justified and unjustified real film violence on aggressive behavior. Journal of Personality and Social Psychology, 23, 21-29. doi:10.1037/h0032868.

Miller, C. F., Lurve, L. E., Zosuls, K. M., \& Ruble, D. N. (2009). Accessibility of gender stereotype domains: Developmental and gender differences in children. Sex Roles, 60, 870-881. doi:10.1007/s11199-009-9584-x.

Moore, S. R., \& Cockerton, T. (1996). Viewers' ratings of violence presented in justified and unjustified contexts. Psychological Reports, 79, 931-935.

Oppliger, P. A. (2007). Effects of gender stereotyping on socialization. In R. W. Preiss, B. M. Gayle, N. Burrell, M. Allen, \& J. Bryant (Eds.), Mass media effects research: Advances through metaanalysis (pp. 199-214). Mahwah: Lawrence Erlbaum Associates.

Pratto, F., \& Bargh, J. A. (1991). Stereotyping based on apparently individuating information: Trait and global components of sex stereotypes under attention overload. Journal of Experimental Social Psychology, 27, 26-47. doi:10.1016/ 0022-1031(91)90009-U.

Preacher, K. J., \& Hayes, A. F. (2004). SPSS and SAS procedures for estimating indirect effects in simple mediation models. Behavior Research Methods, Instruments, \& Computers, 36, 717-731.

Price, V., \& Tewksbury, D. (1997). News values and public opinion: A theoretical account of media priming and framing. In G. Barnett
\& F. J. Boster (Eds.), Progress in the communication sciences (pp. 173-212). Norwood: Ablex Publishing Corp.

Roskos-Ewoldsen, D. R., Roskos-Ewoldsen, B., \& Carpentier, F. D. (2009). Media priming: An updated synthesis. In J. Bryant \& M. B. Oliver (Eds.), Media effects: Advances in theory and research (3rd ed., pp. 74-93). New York: Routledge.

Schein, V. E., Mueller, R., \& Jacobson, C. (1989). The relationship between sex role stereotypes and requisite management characteristics among college students. Sex Roles, 20, 103-110. doi:10.1007/BF00288030.

Sinaceur, M., \& Tiedens, L. Z. (2005). Get mad and get more than even: When and why anger expression is effective in negotiations. Journal of Experimental Social Psychology, 42, 314-322. doi:10.1016/j/jesp.2005.05.002.

Surawski, M. K., \& Ossoff, E. P. (2006). The effects of physical and vocal attractiveness on impression formation of politicians. Current Psychology, 25, 15-27. doi:10.1007/s12144-006-1013-5.

Tan, A. S. (1979). TV beauty ads and role expectations of adolescent female viewers. Journalism Quarterly, 56, 283-288.

Thornton, B., Leo, R., \& Alberg, K. (1991). Gender role typing, the superwoman ideal, and the potential for eating disorders. Sex Roles, 25, 469-484. doi:10.1007/BF00292535.

Tiedens, L. Z. (2001). Anger and advancement versus sadness and subjugation: The effects of negative emotion expressions on social status conferral. Journal of Personality and Social Psychology, 80, 86-94. doi:10.1037/0022-3514.80.1.86.

Valentino, N. A. (1999). Crime news and the priming of racial attitudes during evaluations of the president. Public Opinion Quarterly, 63, 293-320. doi:10.1086/297722.

Viki, G. T., \& Abrams, D. (2002). But she was unfaithful: Benevolent sexism and reactions to rape victims who violate traditional gender role expectations. Sex Roles, 47, 289-293. doi:10.1023/ A:1021342912248.

Ward, L. M. (2002). Does television exposure affect emerging adults' attitudes and assumptions about sexual relationships? Correlational and experimental confirmation. Journal of Youth and Adolescence, 31(1), 1-15. doi:10.1023/A:1014068031532.

Ward, L. M., \& Friedman, K. (2006). Using TV as a guide: Associations between television viewing and adolescents' sexual attitudes and behavior. Journal of Research on Adolescence, 16, 133-156. doi:10.1111/j.1532-7795.2006.00125.x.

Ward, L. M., Hansbrough, E., \& Walker, E. (2005). Contributions of music video exposure to Black adolescents' gender and sexual schemas. Journal of Adolescent Research, 20, 143-166. doi: $10.1177 / 0743558404271135$.

Wilder, D. A. (1984). Intergroup contact: The typical member and the exception to the rule. Journal of Experimental Social Psychology, 20, 177-194. doi:10.1016/00221031(84)90019-2.

Workman, J. E., \& Johnson, K. K. P. (1994). Effects of conformity and nonconformity to gender-role expectations for dress: Teachers versus students. Adolescence, 29, 207-223. 